\title{
"Consumer migration» phenomenon as a result of global migration explosion: catastrophe theory modelling
}

\author{
Maria Pitukhina ${ }^{1, *}$, Vladimir Volokh ${ }^{2}$, and Eugene Pitukhin ${ }^{3}$ \\ ${ }^{1}$ Russian Science Academy, Leninsky prospekt 14, Moscow, Russia \\ ${ }^{2}$ State University of Management, 109542, Ryazanskiy Prospekt, 99, Moscow, Russia \\ ${ }^{3}$ Petrozavodsk State University, 185035, Prospekt Lenina, 33, Petrozavodsk, Republic of Karelia, \\ Russia
}

\begin{abstract}
The article analyzes reasons of spasmodic migrants' mass exodus from Africa and the Middle East in 2015. In order to describe this phenomenon authors propose to use catastrophe theory toolkit, that would help to describe explained phenomenon using particularly "casp catastrophe". Two basic factors were identified in order to develop the model - push factor (conflicts, instability, poverty in the Middle East) and pull factor (western values and aspirations for political and economic freedom and hope for better opportunity). Model's output variable is linked with migration flows intensity to the EU. "Consumer migration»" phenomenon implies that migrants are aimed at not only saving their lives, but also at their well-being upgrade in Western Europe countries. Relevant statistical indicators in various EU countries and the Middle East make it possible to formulate a hybrid model of contemporary global migration explosion, which is a combination of a gravity model and "casp catastrophe" model. At the same time whileperceiving migration drivers and factors, however, we shall admit that migrants' desire to upgradetheir living conditions doesn't contradict the 1951Refugee Convention.
\end{abstract}

\section{Introduction}

Recently, the global migration problem has becomeespecially pronounced. The World Population Prospects Report claims that "From 2000 to 2015, annual net migration to Europe, Northern America and Oceania averaged 2.8 million persons per year. When countries are grouped by income rather than geography, the attraction of high-income countries is even more evident: from 2000 to 2015, high-income countries received an average of 4.1 million net migrants annually from lower- and middleincome countries. Economic and demographic asymmetries across countries are likely to remain powerful generators of international migration within the medium-term future. Large-scale refugee movements have also had a profound influence on the level of net migration experienced by some countries, including those affected recently by the Syrian crisis.

* Corresponding author: maria.pitukhina@gmail.com 
It became obvious that the EU and Russia managed to cope in different ways with the mass influx of refugees. Russian efforts on Ukrainian refugees were highlyappreciated by the UNHCR Representative in Russia BaisaVak-Voya: «It isimpossible to compare living conditions of those who arrived from Ukraine to Russia with living conditions of refugees in Kenya, Jordan, and Lebanon. It is simply incomparable» [1].

Nowadays it is obvious that the EU is looking for a new conceptual model on migration since there is adeep crisis faced by old migration patterns, lack of migration policy regulation, some the EU member-states even failed to work with refugees, others decided to Brexit.

\section{Literature review}

There are still lots of gaps in migration classification.

In 2007 F. Duvel identified 39 types of migrations, and this is one of the most comprehensive classification of migrations in contemporary literature [2]. F. Duvel migration classification is of particular interest due to the fact that heintroducesa completely new types of migration (Yo-Yo migration, new economic migration, rotary migration). He also claims that nomadism became a part of migration and diversifies economic migration from gastarbeiters and labor migration.

For the last five years new terminology has been successfully introduced in scientific literature. Thus, the term «unaccompanied minors» was introduced by E.Grener, A.Levinson, the UN Agency for Refugees, the American Immigration Council $[3,4,5]$. Unaccompanied minors are mostly migrants aged 15-18 coming from Somalia, Libya, Afghanistan, Iraq, Syria, West and Central Africa, who are trying to seek asylum in the EU and the USA. This terminology is becoming rough reality due to contemporary international relations realities, in particular, the refugee crisis.

Nowadays the European Unionis accommodating a large group of senior migrants, some of themare over 60 years old. These people are mostly migrants from Turkey and North Africa (Morocco, Algeria and Tunisia). Quite logically that scientific discourse has recently given a birth toa new term - «senior at sun» [6]. This migrants'category is facing serious difficulties in assessing health care systemdespite the fact of their legal stay at the EU territory. "Seniors at sun" often do not exercise their right to social security.

Recent migration flows increase in the EU and Russia resulted in a new term which is «pending migrant». Due to a large number of requests (for residence permit or asylum) migrant profile is being considered for a very long time by a responsible body [7]. In general, the process is very long.In Finland and Russia a migrant shall wait for 5 years in order to apply for citizenship. On average, there are only $25 \%$ of refugee applications to be satisfied inthe EU. Malta (72\%) and Italy $(62 \%)$ are satisfying the highest numbers of "pending migrant" applications, while Latvia, Poland and Slovakia are demonstrating the lowest numbers. $[8,11]$.

New migrants' category has recently appeared as a result of globalization - theso called global nomads or neo-vagabonds or transmigrants $[9,10]$. These people live untied to a specific country, they often move without having a permanent home or even job. Global nomads are often foreign managers, migrantswho move frequently maintaining the traditions of two or even more societies.

Neo-vagabonds, global nomads and transnational migrants are synonymous. Within the framework oftransnationalism concept a migrant is perceived as aperson accumulating two or even more identities atseveral societiessimultaneously. 


\section{Phenomenon of Consumer Migration in Contemporary Migration Processes}

Nowadays the world community is facing an unprecedented volume of migration and Europe is dealing with the largest displacement of people since WWII. A large share of the people who are migrating are refugees fleeing the war in Syria for example, Turkey accommodates 2 million of Syrian refugees, Lebanon -1,1 million, Jordan - 630 000, Egypt -130000 . These people are planning to be back to their settlements after the war ends. On the other hand, many other migrants do not fit very easily the 1951 Convention definition of refugee.

This has prompted their classification as economic migrants - for example, famous Dutch politician G.Vilders claims that such migrants are considered to be "gelukszoekers" ("hunters for happiness"), the prime-minister of Hungary V.Orban claims that nowadays "the prevailing majority (95\%) of the refugees are economic migrants", and the premier of Slovakia R.Fiko believes that the majority of refugees coming to Europe are economic migrants [12] A rigid classification of migrants as one or the other category not only oversimplifies this complex issue and disregards important nuances but also does not allow the receiving communities and governments to respond in an effective way.

In this context it is highly important to acknowledge and study a new type of consumer migration, one characterized by hybrid nature and prompted by multiple causes at the same time, thus not fitting easily in any of the previously established legal or popular categories or definitions. An example of such "hybrid" consumer migration would be refugees running from the war while at the same time aiming at setting in a place that would allow them to upgrade their life standard.

This new type of migration is prompted by both pull and push factors like:

- Push factor - Conflicts, instability or oppressive regimes and poverty in the Middle East (Syria, Libya, Iraq, Afghanistan), Ukraine and many African countries;

- Pull factor - Western values and aspirations for political and economic freedom and hope for better opportunity penetrating into the Middle Eastern and other societies.

The combination of these two factors leads to mass exodus of migrants from the fragile states in the Middle East and Africa, and Ukraine as a result of recent instability there. On one hand, there is a sustainable change in youth consciousness in all these countries as a result of democratic and human rights values penetrating rapidly due to advancing technology. On the other hand, there are military activities taking place in many of these locations and a real danger to the life and security of the people fleeing.

Current migration processes are being theorized within the framework of various theories including the catastrophe theory. Catastrophe theory application allows to describe accurately and visualize the processes of behavioral responses to various internal and external stimulus [13]. K.Zeeman made a profound generalization on the possibility of emotional behavior modeling in different situations.

This includes the models of human behavior in conflict situations, the model of human being zombieing who came under the influence of some totalitarian sect, and the model of xenophobia growth between different nationalities and cultures as well as some other patterns of human behavior [14, 15].

We believe that factors that contributed to the new hybrid phenomenon of consumer migration in Europe correlate with the factors mentioned above. Thus, the intensity growth factor is a direct consequence of military actions, and disunity factor is a consequence of Western values penetration in the Muslim world. 


\section{Methodological Model of "Consumer Migration"}

The authors of the article believe that the factors under consideration having contributed to the creation of a new "consumer migration" phenomenon in Europe comply with the abovementioned tendencies. For instance, a social frustration ora growing tension factor is a direct consequence of a warfare factor, and a social barriers or a disunity factor is a consequence of Western values penetration into the Muslim world.

The above-mentioned gives the basis for the hybrid migration flows dynamics which is possible to describe by means of catastrophe model of consumer migration (Figure 1).Amount and intensity of migration flows as a phase variable in on vertical axis. On the contrary to the prison riots model developed by T.Poston and I.Stuart the factor correlating to the phase variable is the degree of Western values and aspirations for political and economic freedom penetration whichresulted in consumer mentality. At the same time the splitting factor of the model is military actionsintensity. Under the military action factor we understand such consequences as number of deaths among civilians in a restricted area (daily), loss of property, loss of livelihood means, etc.

Both in the absence of military actions and consumer mentality a stable level of migration will bemaintained, that corresponds to point A1 in Figure 1.

Migrants'flowsto developed countries will increase with consumer mentality growth and low military actions, but remain within the quotas. This process will take place to a certain threshold that corresponds to a logistic curve from the point A1 to the point of the surface A2. Thus, under low intensity warfare and high consumer mentality, the system will tend to moderate level of migration.

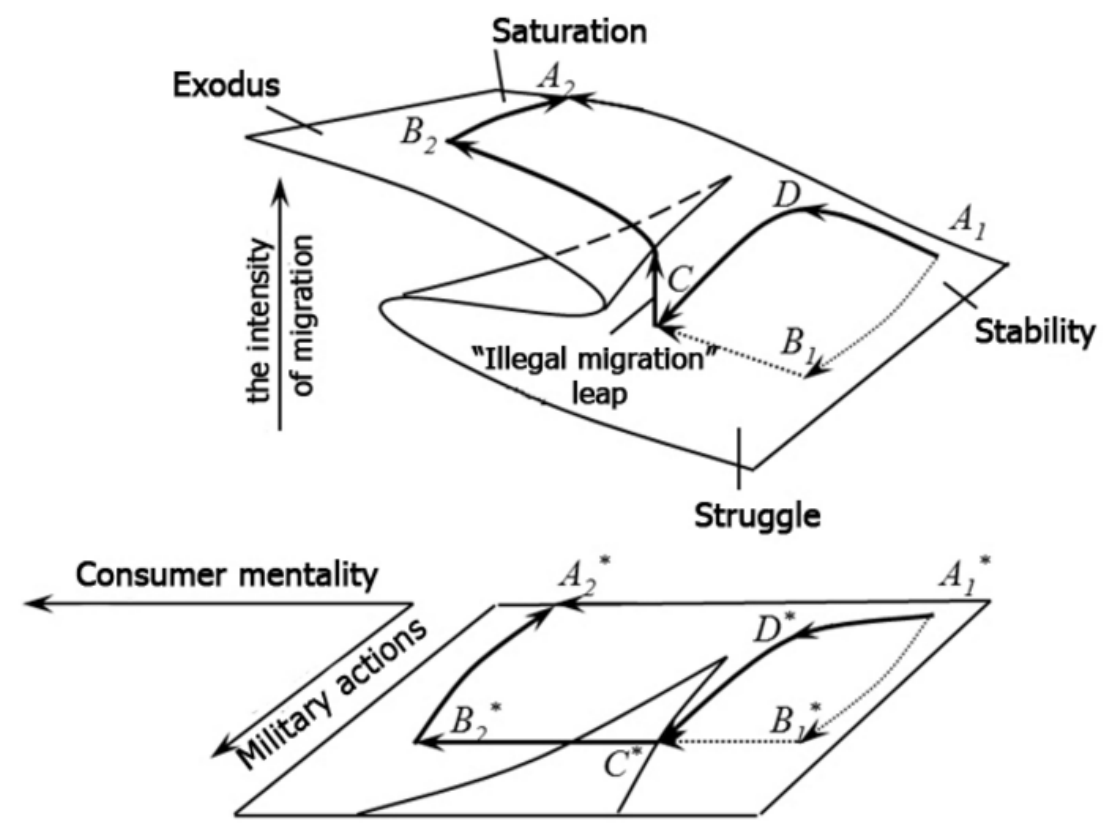

Fig.1. «Consumer migration» model.

According to the catastrophe theory in the absence of consumer mentality and under military actions youth would take probably patriotic position, which would correspond to the trajectory $\mathrm{A} 1-\mathrm{B} 1$. 
If consumer mentality growth corresponds to military actions growth, the further process could be developed in accordance with the trajectory from the point $\mathrm{B} 1$ to the critical point $\mathrm{C}$, which means thatin terms of a very slight consumer mentality increase the system could make a catastrophic leap moving straightly to the point B2. Such developments could be interpreted as mass exodus.

Authors of this article argue that current situation with refugees from the Middle East corresponds to the trajectory $\mathrm{A} 1-\mathrm{D}-\mathrm{C}-\mathrm{B} 2$.

The A1 -D trajectorycorresponds to moderate level of migration into Europe when migration quotasare not satisfied. Military actions growth corresponds to the trajectoryD $\mathrm{C}$, where migration intensity is close to critical point - C. At this very point wish for better life and hope for better opportunity or military actions growthcould provoke catastrophe - a sharp leap of migrationthat would make system go into a mass exodus ( $\mathrm{C}-\mathrm{B} 2$ trajectory).

According to U.Plotinsky, transitional processes and social systems'crises can have three options as resolution:

1) systemcollapse or destruction, its elements are caught up by other systems;

2) reform which is a gradual restructuring of the core system leading to qualitatively new system emergence;

3) revolution - sharp, abrupt change of thecore system, catastrophic transition from one condition to another [Plotinsky, 2001].

Obviously the most acceptable option for Europe is a reformthat includes bothmigration legislation revisionand developmentsaimed at tension factor reduction resulted fromhostilities cessation in Syria and Iraq.

The explaining factors for both "consumer mentality level" and "military action intensity" used in a catastrophe theory model and presented by the authors are therefore absent in statistics.In a broader sense, they resulted from a generalized impact of other factors that were suitably selected from a number of existing statistical indicators.

Such indicators might include GDP per capita, income per capita, average wage, human development index, life quality index, happy planet index, life expectancy, infant mortality,crime level, external causes fordisease and mortality, including mortality caused by murder and military actions, unemployment, cultural level, etc.

The dependence of explanatory factors on the above-mentioned indicators could be presented in a form of a gravity model. Gravity models are widely used for determining mobility and number of customers travelling between settlements, cities and countries to use the services thatare not provided at home. Due to attraction, or gravitation, of these groups of people by the corresponding service, such models were named "gravity models" by analogy with Newton's law of universal gravitation.

For example, Reilly's gravity model [16] (Reilly's law of retail gravitation) is like this larger cities attract larger number of customers who are ready to travel longer distances to large shopping centres, and gravity is proportional to the amount of population and local trade turnover and inversely proportional to the distance to them squared.Using another gravity model, the level of economic cooperation between two cities can be determined - a number of commuting movements [17].Huff's gravity model is a cutting-edge technology which is actively used in developed countries for calculating potential turnover of locations that retail chain considers for the opening of new shops.

The paper [18] studies the possibility of a gravity model application to the analysis of modern intraregional migrations. The author shows the analysis of a migration picture of Novgorod and Pskov oblasts by means of gravity modelling.A dynamic modified gravity model of migration on the basis of a difference equation was proposed in the paper to develop on its basis a model of internal and external migration flows for the Russian Federation's regions. The article [1] studies the major problems associated with forecasting foreign and regional labour migration in Russia, analyses the main ways of labour 
migration processes modelling, justifies the possibility of gravity models application, suggests a modified gravity model as well as summarizes the results of prediction calculations for migration flows from CIS countries to the Central Federal District of Russia.

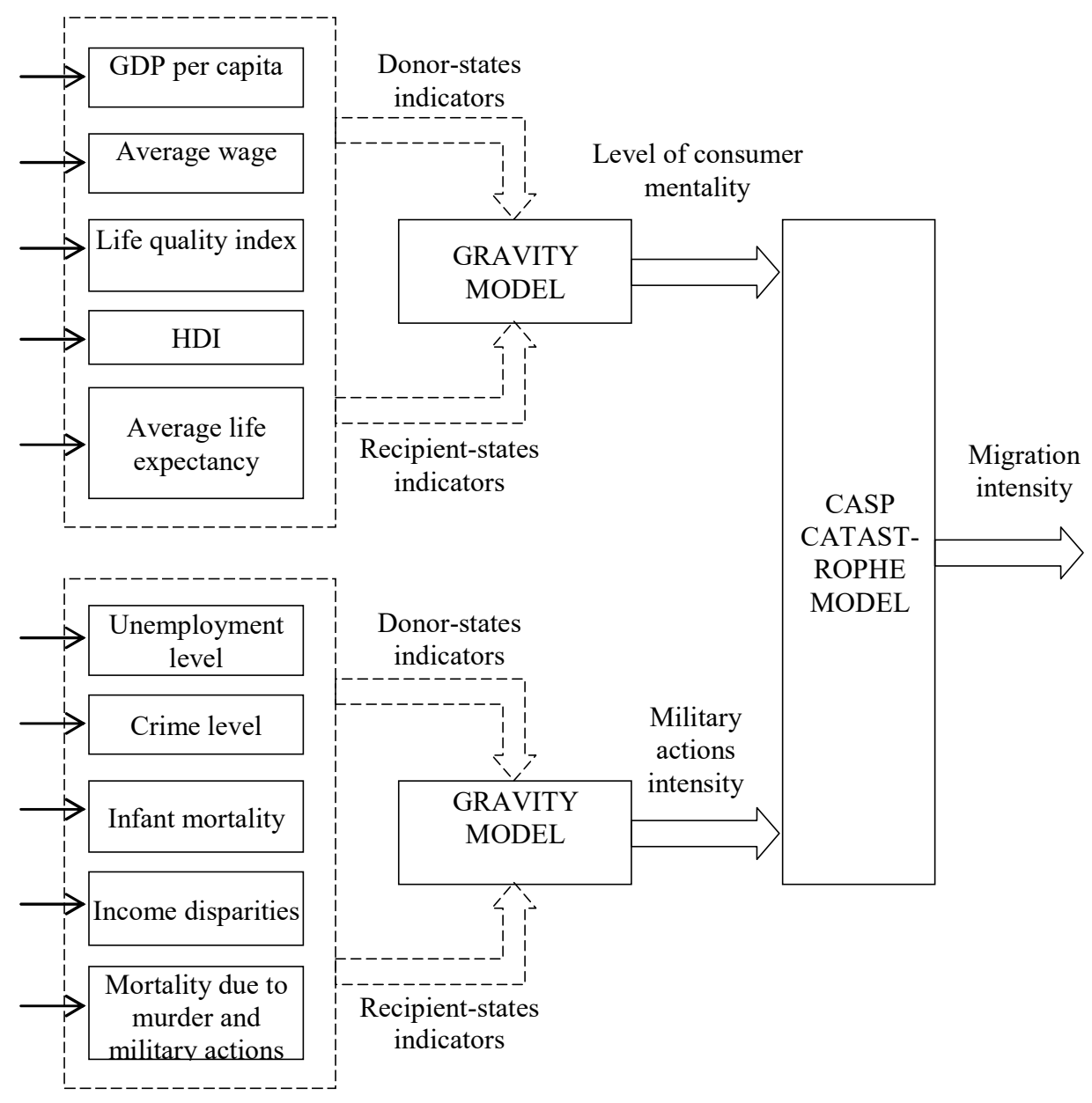

Fig. 2. "Consumer migration" hybrid model structure.

\section{Results and discussion}

To sum up, diverse forms of gravity equations are used for assessing the number of migrants nowadays.

The authors of this article suggest using a gravity model in the form of multiple linear regression for evaluating numerical values of governing factors of $a$ and $b$ cusp catastrophe models. This choice is justified by the fact that such a form is analogous to the approach described in the paper [Poston, Stewart, 1980] when a total of weighted values of a weekly number of visits to a doctor, a complaint of a malaise during work, sanctions,imposed by the prison governor, and charity visits was used as a measure of 
tension.Disunity was measured by a total number of prisoners in solitary confinement and prisoners asking for separation. Then the regressors would be relevant statistical indicators differencesbetween donor-states (Africa and the Middle East) and recipient states (the EU). This model corresponds to reality and is well interpreted as soon as migrants from the Middle East actually migrate to countries with a higher GDP per capita and a lower crime level. These models are considered as a specific case of S. Stauffer's gravity model where country's life standards is viewed as an influence factor (or input variable).

Thus, based on a reviewed approach a hybrid model of current migration explosion is proposed combining both gravity model and the "cusp catastrophe" model (Figure 2).

In the Figure 2 a hybrid model of consumer migration is presented, where the output variables for the gravity model are input variables for the "cusp catastrophe" model.

In the future, hybrid model formalization in a form of mathematical model wouldcontribute to numerical evaluation ofmigration processes intensity as well as to key factors identification. This makes it possible both to predict such explosive situations and to make appropriate decision-making in order to prevent them.

\section{Conclusion}

Authors believe that the predominance of one of the above-mentioned two factors (conflicts in the Middle East or the penetration of Western values in the Middle Eastern societies) will not mandatorylead to a consumer migration phenomenon.

According to catastrophe theory, in case thepush-factor (military conflicts) is prevailing peoplewould rather flow to border camps. Consumption psychologywithout any war actions (pull-factor)would hardly cause such a huge wave ofpeople who wanted to improve their financial situationsignificantly.

Authors suggest that one should not expect that refugees will come back and rebuild their country, which is also confirmed by simulation results of migration processes in the framework of catastrophe theory.

At the same time, solution is seen as a reduction of military actionsthat would lead tomigrants' flowreduction.

Despite the fact that we are trying to perceive migration drivers and factors, however, we shall admit that migrants' desire to upgradetheir living conditions doesn't contradict the 1951Refugee Convention.

\section{References}

1. Ju. Andrienko, S. Guriev, Razrabotka modeli vnutrennih $i$ vneshnih migracionnyh potokov naselenija dlja regionov Rossijskoj Federacii (Russia Economic School, 2006).

2. F. Duvell, Prostranstvennaja mobil'nost' naselenija: indikatory, kategoriiitopologii (Moscow, 2007).

3. A. Levinson, Unaccompanied Immigrant Children: A Growing Phenomenon with Few Easy Solutions (2015). http://www.migrationpolicy.org/article/unaccompaniedimmigrant-children-growing-phenomenon-few-easy-solutions

4. A. Grenier, Migrant children flee violence in home countries (2015). immigrationimpact.com/2014/06/12/migrant-children-flee-violence-in-home-countries

5. Children on the run: The UN Refugee Agency Report. http://www.unhcrwashington.org/sites/default/files/1_UtAC_Children $\% 20$ on $\% 20$ the $\%$ 20Run_Full\%20Report.pdf 
6. A.Tran, N. Minh, D. Ushakov, Int. J. of Recent Technology and Engineering 8(2S11) 3883 (2019).

7. A. Krasteva, Migrants and refugees. Equitable education for displaced populations (Information Age Publishing Inc, 2013).

8. The UN Refugee Agency (2015). www.unhcr.ru/

9. S. Glick, L. Bash, C. Blanc-Szanton, Annals of the New York Academy of Sciences 645 (1992).

10. H. Mai, H. Van, D. Ushakov, Int. J. of Recent Technology and Engineering 8(2S11), 3876 (2019).

11. E. Rievajová, A. Př́vara, K. Mayerová, EUrASEANs 5(18), 55 (2019).

12. N. Trofimova, V. Razumovskaja, Gravitacionnaja model' trudovoj migracii (Moscow, 2011).

13. E. Zeeman, Catastrophe theory (Scient. Am., 1976).

14. K. Lorenz, On aggression (London, Methuen, 1966).

15. How many migrants to Europe are refugees? www.economist.com/blogs/economist-explains/2015/09/economist-explains-4

16. W. Reilly, The law of retail gravitation (New York, 1931).

17. D. Huff, Parameter Estimation in the Huff Model (ArcUser, 2003).

18. P. Vasilenko, Herald of Baltic Federal University 7, 153-157 (2013). 